\title{
Treatment of Brodie syndrome
}

\author{
M. Sebbag ${ }^{1}$, A. Cavaré ${ }^{2}$ \\ 1 Resident, Post-graduate degree in Dentofacial Orthopedics Bordeaux \\ 2 Clinical Assistant, Bordeaux
}

\begin{abstract}
Brodie Syndrom is a rare form of transverse malocclusion, characterized by excessive occlusion of the lateral zones, the contact is established between the palatal surfaces of the maxillary teeth and labial surfaces of the mandibular teeth, so that there is no intercuspidation of the maxillary and mandibular molars. It not only adversely affects chewing and muscle functions, but also impairs normal growth and development of the mandible if left untreated, with the possibility of jaw deformities. The anomaly may be bilateral or unilateral, clinical examination will search for signs of asymmetry or mandibular lateral deviation. Additional tests are needed to point out the alveolar or basal location of the malocclusion. Schematically, the therapeutic means used will seek to contract the maxillary arch, and expanding the lower arch. Orthodontic treatment is complex but the bone anchorages provide some help in this context. Nevertheless, the therapy is often orthodontic and surgical and must move towards unconventional surgeries such as symphyseal distraction.
\end{abstract}

\section{KEYWORDS}

Brodie syndrom, brodie bite, orthodontics, orthognathic surgery

\section{INTRODUCTION}

Brodie syndrome is an abnormality of transverse occlusal relationships and was named after Allan G. Brodie, who was the first author to present the case of a patient with this malocclusion in 19527. Other names can be found in the literature: Brodie bite, exaggerated occlusion, or even scissors bite. The term "syndrome" seems inappropriate as medical records differ among individuals, with no specific occlusal disorder or any other clinical, physiological, biological, or radiological symptoms ${ }^{14}$. It is only an abnormal occlusal condition without precise details regarding the structure causing the malocclusion, the underlying etiology, or the presence of associated symptoms.

This malocclusion is clinically defined by a complete lateral position of the maxillary arch in relation to the mandibular arch. The mandibular arch is totally imbricated inside the maxillary arch. Contact is established between the palatal surfaces of the maxillary teeth and the vestibular surfaces of the mandibular teeth. The base of the malocclusion may be maxillary, resulting in a transverse basal excess (maxillary exognathia) ${ }^{5}$ or alveolar excess (maxillary exoalveolie), 
which result in mandibular transverse constriction. Mandibular alveolar anomalies, which are widely accepted in the literature ${ }^{2,4}$, are distinguished from mandibular endognathia or basal anomalies, which are not recognized by all authors $^{34}$ and most often correspond to a general hypodevelopment of the mandible or micromandibular deformity. Both jaws may be involved in the frequent entanglement of the skeletal and alveolodental levels.

This anomaly can be symmetrical (bilateral) or asymmetrical (unilateral) and appear in both temporary and mixed $(0.4 \%$ to $1.0 \%$ of the population) dentition or permanent dentition $1.0 \%$ to $1.6 \%)^{37}$. It can be combined with all other types of dysmorphoses in the anteroposterior and/or vertical levels, thus greatly complicating its treatment. However, a sagittal shift with a retruded mandible may lead to Brodie occlusion; simulation of the mandibular propulsion then makes it possible to attenuate the transverse discrepancy of the arches.

\section{CLINICAL SEMIOLOGY}

\section{The diagnostic process}

Having Brodie syndrome is rarely cause for going for a consultation, and it is more often discovered by chance. As esthetic repercussions are limited, patients are unaware of their malocclusion. At the time of anamnesis, complaints of pain and functional issues associated with manducatory difficulties ${ }^{8-10}$ (absence of posterior contacts, prolongation of masticatory cycles, and interference in diduction) in the vestibular, mandibular, and gingival palatal bites ${ }^{9}$ when there is significant lateral overbite and in the posterior and lateral joint constraints. The examination of the temporomandibular joints (TMJs) highlights articular disorders such as luxation, cracking, or clicking, which is associated with highly disturbed mandibular dynamics; however, these internal disturbances in the TMJs are not systematic.
The extraoral repercussions of Brodie syndrome are few because soft tissue thickness can mask malocclusion. However, unilateral forms are more strongly associated with facial asymmetry (laterognathia/mandibular deviation).

Intraorally, the maxilla presents a wide arch (increased intercutaneous and intermolar distance) and a flattened palatal arch (morphogenetic role of the upper lingual posture). Transversally, the examination of alveolar processes facilitates a differential diagnosis between exognathia and transverse maxillary excess. In maxillary exognathia, the orientation of the processes is vertical (absence of alveolar compensations) or palatal (existence of alveolar compensations). However, when there is transverse maxillary excess, the processes are vestibularly inclined. In the mandible, a narrow $\operatorname{arch}^{4}$ (decrease in arch length and intercanine distance) is often observed with frequent linguoversion of 
the lateral areas and an increase in the curve of Wilson ${ }^{18}$.

In adults, the deformations of the mandibular arch reach a very severe stage; the form and continuity of the arch are then strongly disturbed with the lateral areas seemingly "impacted," and the area where the dental bites are located is very linguoversed on the mandibular vestibular gingiva and palatal mucosa.

An open bite or lateral supraclusion in the lateral sectors is often associated with the extrusion of the posterior sector due to the absence of occlusal contact. A class I and II dental occlusion is most often observed, and though less common, a class III angle occlusion is found.

It is the exaggerated transverse relationship that characterizes this "syndrome." However, there are several clinical forms of this condition:

- Bilateral Brodie occlusion: the malocclusion is symmetrically found on the left and right sides. This form is more often associated with skeletal and occlusal class II types with incisive and lateral supraclusion. A deviation of the median incisors is found on an asymmetrical arch with dental overcrowding (Fig. 1).

- Unilateral Brodie occlusion: the abnormality is present on only one side. We notice an occlusal plane shift of the frontal plane alone if the affected side displays lateral supraclusion. The maxillary and mandibular occlusal planes then converge on the affected side. Moreover, mandibular lateral deviation/laterognathia is often associated with this unilateral form; hence, there is deviation of the lower interincisal point (Fig. 2).

- Brodie occlusion localized to a tooth: most often related to an eruption anomaly, this scissor occlusion can be uni- or bilateral and most often involves the second molars. Other teeth may be affected, particularly in cases of iatrogenic therapeutic gestures or prolonged persistence of deciduous teeth (Fig. 3).

Standard complementary examinations are supplemented by frontal
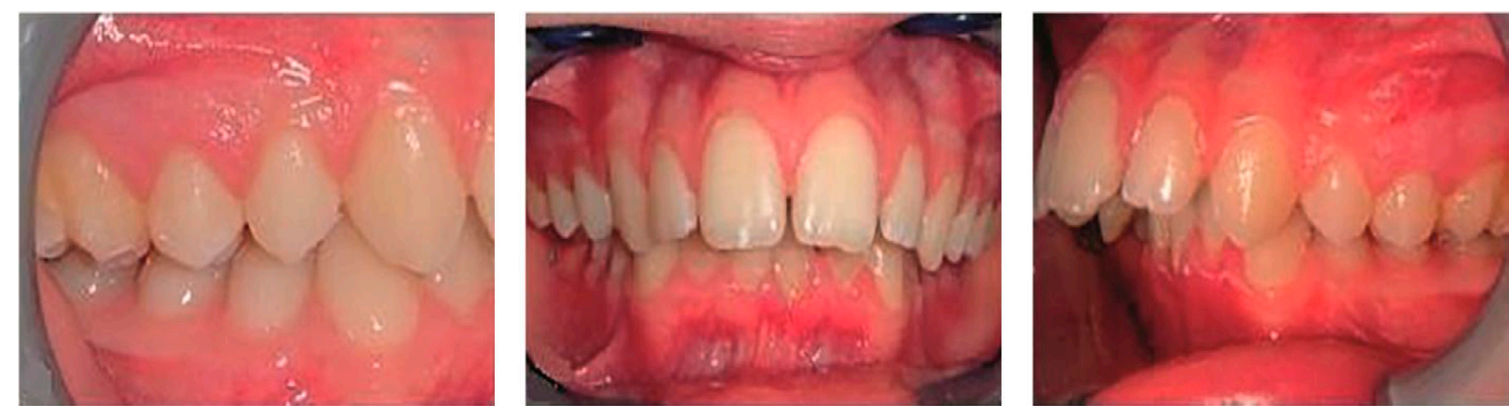

Figure 1

Intraoral views of bilateral Brodie occlusion

(Pr Boileau). 

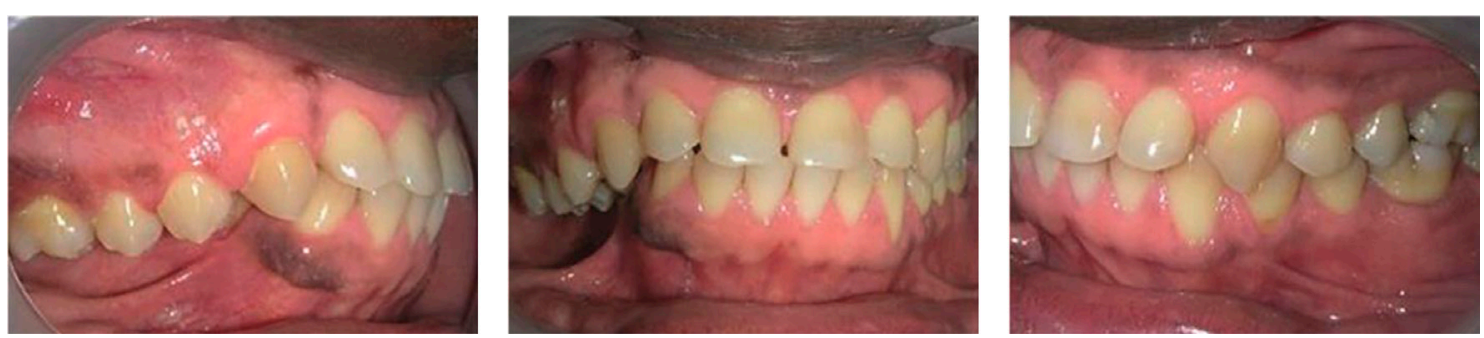

Figure 2

Intraoral views of unilateral Brodie occlusion (Dr Bardinet).
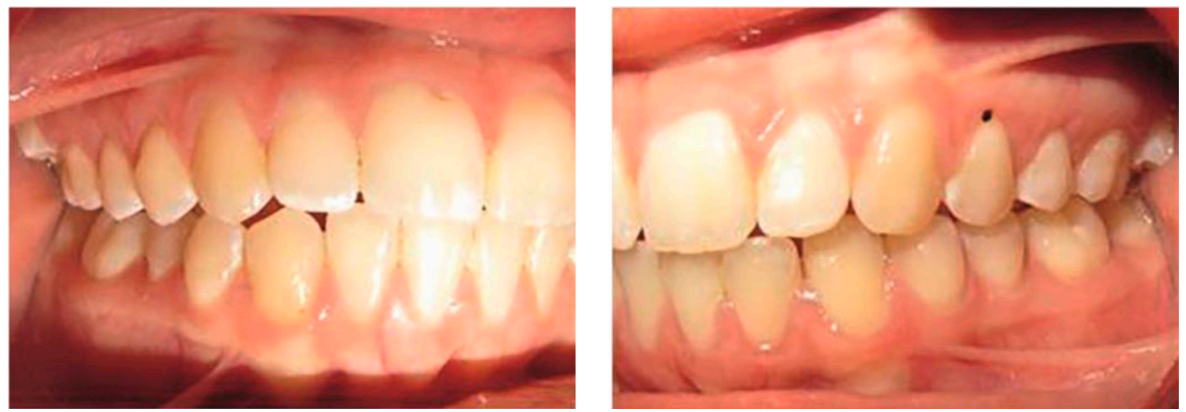

Figure 3

Intraoral views of Brodie occlusion located at the second molars (Dr Sebbag).

incidence radiography, which is perfectly adapted to the study of transverse anomalies. It helps refine the diagnosis of Brodie syndrome by objectifying the transverse dimensions of the bone bases and their symmetry, orientation of the alveolar processes, transverse ratios of the jawbones, presence of facial asymmetry, and position of the tongue and its relations with the palatal arc. Three-dimensional sectional imaging such as cone-beam computed tomography may be added to the examination to study the cortical thickness and the possibilities of alveolar compensations among other things.

\section{Etiological Diagnosis}

The etiologies of Brodie syndrome are uncertain and differ depending on authors. In terms of hereditary and congenital etiologies, Ramsay ${ }^{40}$ was the first to report the case of two first cousins with a similar malocclusion that was surgically treated and to assume a "hereditary influence." Similarly, Gar$\mathrm{cia}^{14}$ observed three siblings in whom one sister and one brother had Brodie syndrome. In our hospital department, we were able to find a mother and son having unilateral Brodie syndrome; in both of them, the affected side was different (Fig. 4). 

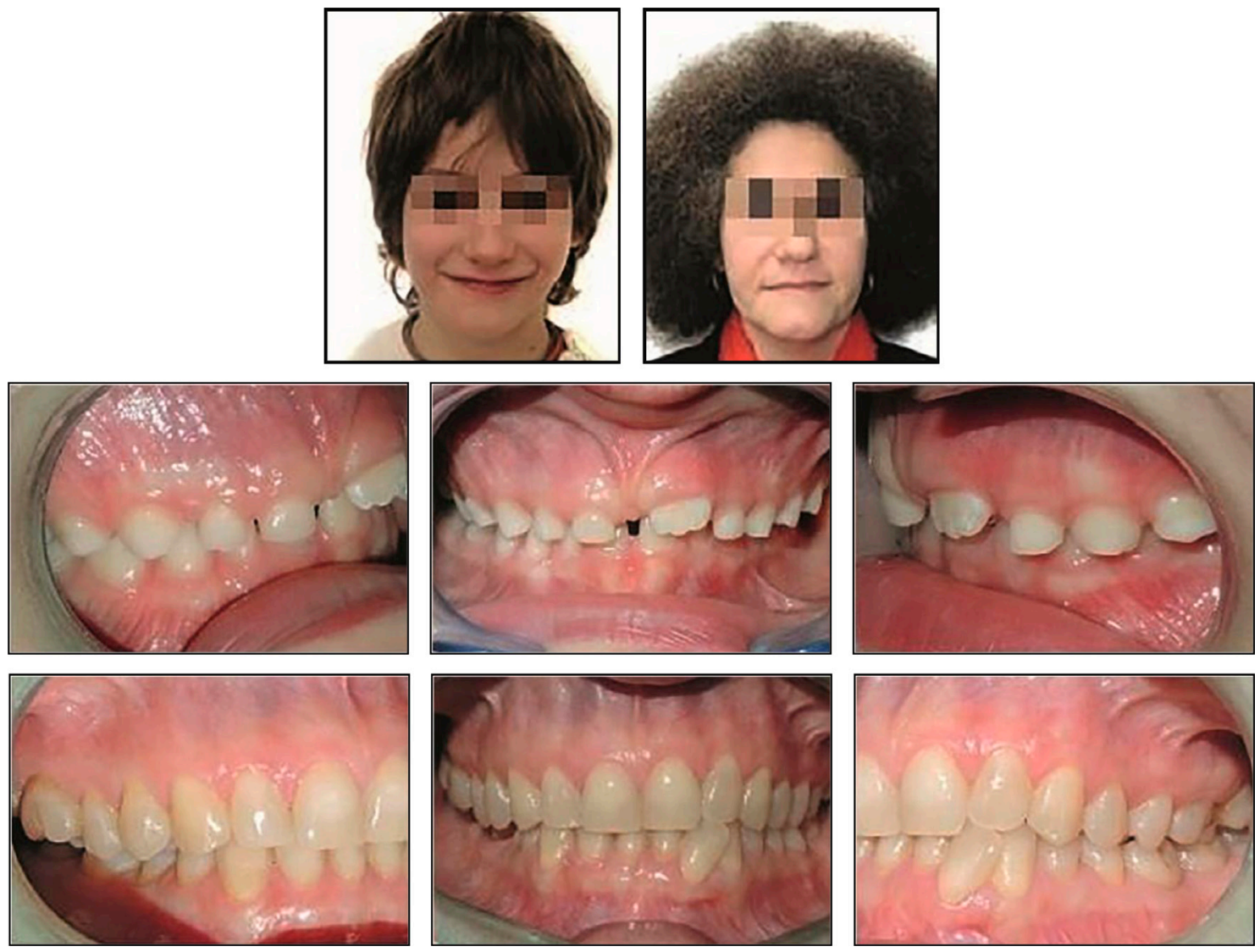

Figure 4

Brodie syndrome found in a mother and her son (Dr Cavaré).

\section{Genetic Etiologies (major syndromes)}

Brodie occlusion was found in patients afflicted with William-Beuren syndrome or Robin syndrome without however establishing a direct causal relationship.

\section{Functional Etiologies}

Many authors have suggested a functional etiology of the malocclusion. According to Brodie, as the morphology of the archways generally conforms to the shape of the tongue, if the tongue presents a high posture and exerts a strong force on the maxillary arch, it is possible to observe an exaggerated increase in the maxillary base and a mandibular arch completely enveloped by the upper arch during buccal closure ${ }^{6}$. Bassigny ${ }^{1}$ believed that the high position of the tongue induced transverse mandibular deficiency at the alveolar level and therefore resulted in a defect in transverse mandibular development rather than a transverse maxillary excess. Biourge ${ }^{10}$ associated this postural anomaly with an excess volume abnormality, which gives the dental arches 
particular forms. Bouvet, Conley, and Legan $^{12,47}$ also suggested a functional and muscular etiology and lingual habits that aggravate the transverse maxillary excess or deficiency. Finally, Dahan ${ }^{14,47}$ proposed a combination of a volume abnormality, a change in posture, and/or a lingual mobility disorder.

\section{Skeletal Etiologies}

As we have already mentioned in the severe skeletal class II, the retruded position of the mandible allows the maxillary arch to confine the mandibular arch completely ${ }^{43}$. In this context, the Brodie occlusion constitutes an occlusal lock which inhibits the mandibular growth, which perpetuates the phenomenon and aggravates the class $\mathrm{II}^{4}$. Moreover, the absence of contacts between the anterior maxillary and mandibular sectors prevents any stimulation of the alveolar bone, frequently leading to a slowing down of the eruption pattern ${ }^{43}$.

\section{Dental Etiologies}

Dental eruption anomalies, the etiology of which may be genetic (eruption pathway anomaly) or environmental (a history of trauma or delayed persistence or even ankylosis of a temporary tooth), can cause a permanent tooth to erupt in exaggerated occlusion (Fig. 5).

\section{latrogenic Etiologies}

Treatment for uncontrolled maxillary expansion may promote the development of Brodie syndrome (Fig. 6). Removing the equipment (disjunctor, Quad Helix) facilitates spontaneous correction in most cases.

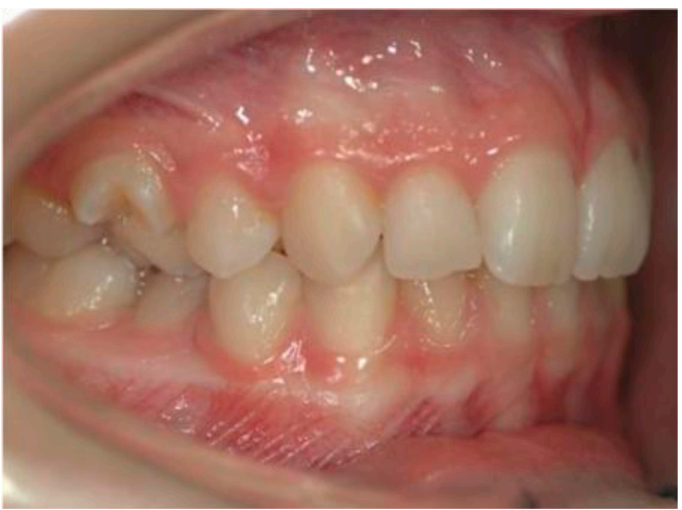

Figure 5

Persistence after normal exfoliation date of 55 resulting in an exaggerated occlusion eruption of 15 (Dr Cavaré).

\section{Prognosis without treatment}

The prognosis in the absence of therapeutic intervention is bleak. During periods of growth, Brodie syndrome creates occlusal locks that inhibit mandibular growth, thus aggravating the skeletal class II type. Similarly, the functional inefficiency of scissor occlusion, particularly the unilateral version, leads to mandibular lateral deflection in search of relative occlusal stability. This lateral deviation induces asymmetric solicitations of the TMJs that are likely to cause facial asymmetry. On the dentoalveolar plane, the absence of cuspidian contacts permits the extrusion of the lateral sectors and has unlimited space and no fixed duration. This extrusion accentuates interferences and occlusal constraints and significantly complicates treatment. Finally, the aggravation of the dysmorphosis also leads to an increase in functional discomfort and painful symptomatology, particularly in the TMJs. 

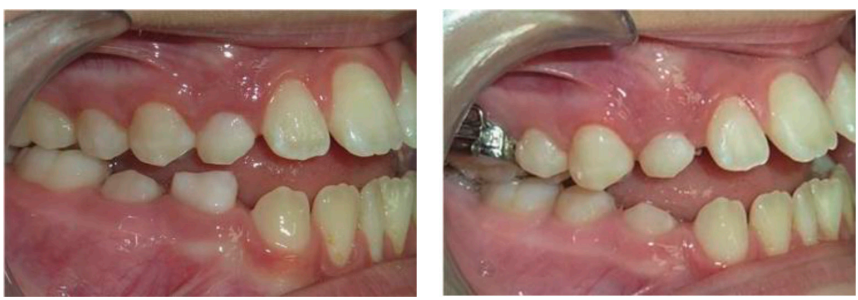

Figure 6

Uncontrolled expansion with a Quad Helix, responsible for the exaggerated occlusion of 16 (Dr Cavaré).

\section{CURRENT THERAPEUTICS IN BRODIE SYNDROME}

The therapeutics used (orthopedics, orthodontics, or orthopedic or segmental surgery) seek to transversely coordinate the dental arches by contracting the maxilla and its arch and/or widening the mandible and its arch.

Therapeutics must be used as early as possible, if one seeks to accelerate maxillary growth by orthopedic means, particularly as malocclusions are self-sustaining and aggravated by occlusal locks as well as by the extrusion of affected sectors, which is not limited by masticatory forces.

\section{Prevention}

Given that the etiology of the malocclusion found in Brodie syndrome is multifactorial, it is difficult to give effective preventive advice. In general, adequate functional behavior should be promoted at an early age and parafunctions should be eliminated. It is advisable to extract temporary or ankylosed deciduous teeth and to monitor the evolution of permanent teeth. To prevent iatrogenic gestures, orthodontists must limit the use of maxillary expansion in case of Brodie syndrome without maxillary endognathia or posterior cross occlusion and anticipate the confounding effects of installed devices.

\section{Orthopedics}

According to Brodie (1), an overexpanded maxillary arch should be treated as soon as possible, the aim being to create a more symmetrical relationship between the upper and lower arches, allowing each arch to be in occlusion at the time of buccal closure. Thus, when the diagnosis is made at an early stage, it is strongly recommended to correct this malocclusion to limit functional consequences and any mandibular locking. ${ }^{42}$

Orthopedic treatments follow the principles of maxillary contraction and mandibular expansion/advancement. Treatment may become complex due to the presence of lateral supraclusion. Occlusion-enhancement devices (resin blocks, a maxillary retroincisal plane, and a maxillary elevation plate) may be necessary to remove any interference and facilitate articular movements.

In the maxilla, the devices that are used to stimulate transverse contraction of the maxilla at the alveolar level are most often expansion devices, 
which have been redirected to be used in reverse. Basal maxillary contraction requires surgical intervention ${ }^{4}$; real maxillary contraction cannot be achieved because median palatal sutures cannot be resorbed. Alveolar contraction is accompanied by the slowing down of the transverse growth of the maxilla. The mandible then catches up with the transverse discrepancy by its sagittal growth and by a slight transverse component linked to Enlow's $\mathrm{V}$ principle.

\section{Maxillary split "contraction" plate}

It is a split maxillary plate (Schwartz plate) consisting of two parts supporting the posterior areas and is connected by a central screw (actuator) in the "open" position. Occlusal resin return may be added to the apparatus to facilitate articular movements, but this occlusal elevation may be responsible for posterior mandibular rotation if the plate is worn over a long period, which worsens the class II sagittal discrepancy (Fig. 7). Hooks are used to keep the device in place; otherwise, its retention can be assured by a resin vestibular feedback mechanism in the lateral sectors.

The plate should be worn as much as possible during the day (except during meals) and at night, which requires the full cooperation of patients. Activation is performed once a week at a rate of one quarter of a turn of the screw (contraction of $0.25 \mathrm{~mm}$ ). At this rate, the correction of the malocclusion is done within 6-9 months.

In case of unilateral Brodie syndrome, it is possible to use this apparatus asymmetrically owing to its unique design ${ }^{13,19}$. The device is segmented into two asymmetrical parts to isolate the affected sector (exaggerated joint) on one side and the anchoring sector on the other side (Fig. 8).

The objective is to contract the maxillary hemiarch on the side of Brodie occlusion, parallel to the suture, without contracting the contralateral area (risk of transverse maxillary deficiency). The principle of activation remains the same.

In the literature, patients treated with this device showed a decrease in temporary intermolar $(3-5 \mathrm{~mm})$ and temporary intercanine (1-2 $\mathrm{mm}$ ) diameters after treatment, therefore underlining the alveolodental effect of the device $^{13,42}$.
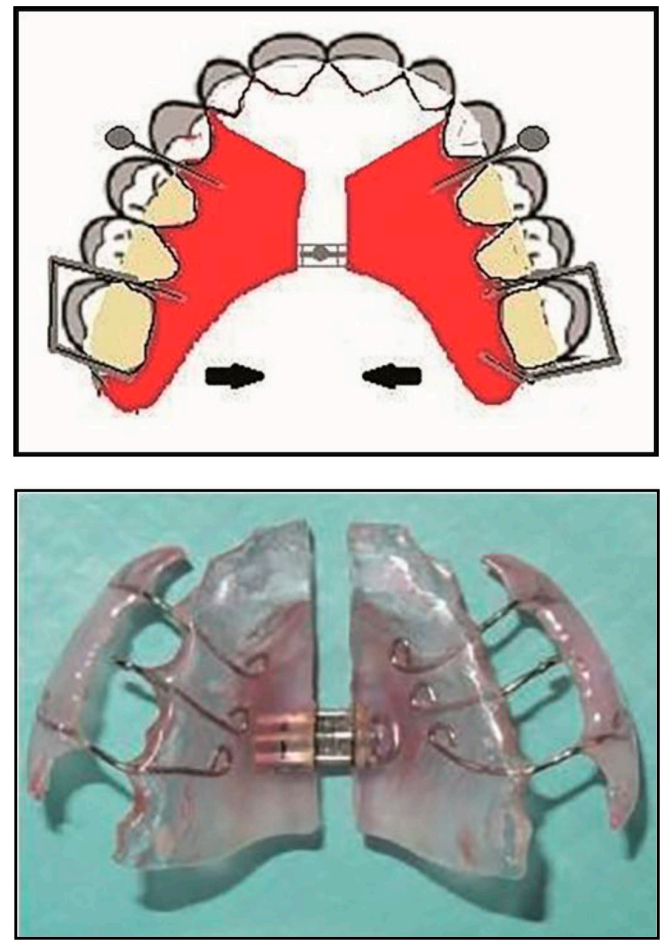

Figure 7

Maxillary split "contraction" plate (symmetrical action) (Dr Sebbag). 


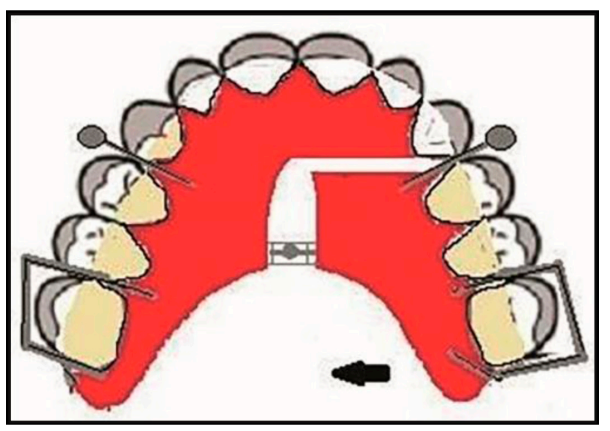

Figure 8

Maxillary split "contraction" plate (asymmetrical action) (Dr Sebbag).

\section{Quad Helix}

The fixed nature of the device and no manipulation or cooperation of patients are its main advantages. This device is found in several forms in the literature $^{22,46}$. Nojima et al. ${ }^{31}$ used a Quad Helix modified with resinous splints to correct bilateral Brodie occlusion in a 9 -year-old patient. Contraction activation is bilaterally performed at anterior helices using the amount necessary to correct the malocclusion. On the biomechanical plane, the contraction movement is accompanied by an intrusion of the teeth supporting the apparatus, which contributes to vertical correction and facilitates articular movements. Valencia also reported the use of this type of device in patients aged 4-7 years who suffer from Brodie syndrome ${ }^{32}$. The Quad Helix is made from thick steel (diameter of .036); it is shaped like a "W" and is attached to the second temporary molars. The vestibular arms are welded onto the molar bands and reach as far as the temporary canines to support the lateral areas.

When faced with a unilateral clinical version of the syndrome, with the aid of this device, we attempted to increase the anchorage of the side in normal occlusion (addition of a lateral arm, radiculopalatal torque, management of the temporary canine) (Fig. 11).

\section{Hyrax Disjunctor}

A Hyrax disjunctor can also be used on bands or splints. It is constructed in the open position, and its activation causes bilateral contraction of the maxillary arch (Fig. 9). This device must be activated every $2-3$ days $(0.25 \mathrm{~mm}$ constriction/activation) and can create coronopalatal tipping of the teeth (associated risks of root fenestration and the smile no longer seems as "wide"). It is therefore a device to be used with great precaution and is not adapted to unilateral forms where it is possible to create an inverted articulation on the initially correct side ${ }^{13}$.

The devices used bring about mandibular expansion exclusively at the dentoalveolar level. Mandibular symphyseal sutures can be introduced at the age of 1 year, and the possibilities of transverse mandibular orthopedic action remain limited to periosteal remodeling. This action corrects the linguoversion of the posterior areas generally present in Brodie syndrome.

\section{Plate with an expansion actuator}

It is a mandibular plate with a median expansion actuator. The device is retained by ball hooks or Adams hooks located between the temporary molars and the first permanent mandibular molar ${ }^{33}$. When activated, the actuator increases the width of the mandibular arch and corrects the orientation of the alveolar processes in case of 


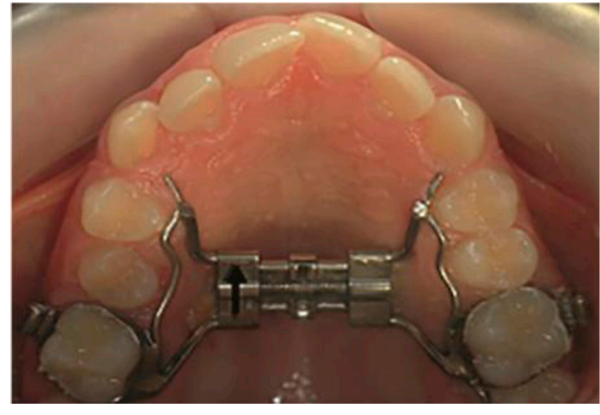

Figure 9

Reverse activation of the disjunctor's actuator during "contraction" (Dr Cavaré).

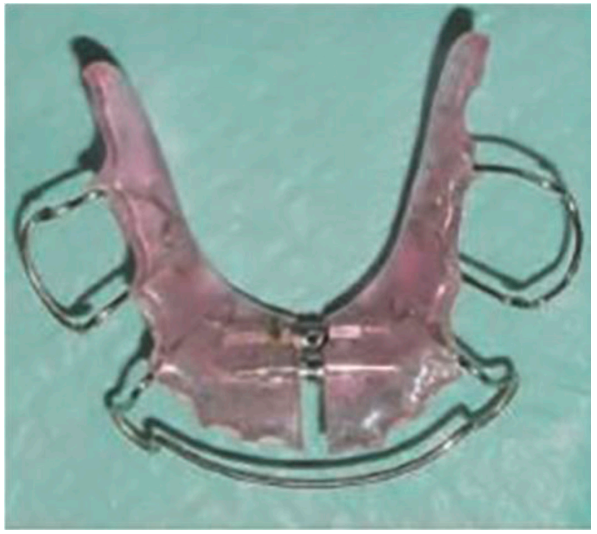

Figure 10

Removable mandibular expansion plate (Dr Cavaré).

transverse mandibular deficiency ${ }^{32}$. As a removable device, its effectiveness is determined by the cooperation of patients (it must be worn as often as possible). In addition, the large volume of the device may interfere with the tongue, making it difficult for some patients to tolerate ${ }^{15,33}$ (Fig. 10).

\section{Crozat Device}

The apparatus consists of a lingual bow welded to molar bands and two arms framing the lingual surfaces of the lateral sectors (Fig. 11). Front springs, hooks, or whisks can be added to achieve isolated dental movements. This device enables numerous actions, notably, transverse expansion, remodeling of the mandibular $\operatorname{arch}^{31}$, and straightening of the mandibular molar axes $^{25}$. This apparatus has the advantage of being fixed inside the mouth.

\section{Mandibular Arnold Expander}

Mandibular Arnold Expander is a fixed device that facilitates slow mandibular alveolar expansion without soliciting the cooperation of patients. The first molar bands are interconnected on one side by a hollow lingual tube of diameter .040 and on the other side by a steel bow around which an open helical nickel-titanium spring is inserted during compression. The alveolar action of the device makes it possible to straighten the lateral sectors (average transverse gain of 2-3 $\mathrm{mm}$ at the canine level) to slightly displace the molars to a more distal position and reduce anterior overcrowding.

Kravitz $^{48}$ used this device in conjunction with maxillary contraction (disjunctor in reverse position) in a 14-year-old adolescent patient with bilateral Brodie syndrome. The malocclusion was successfully corrected within 3 months.

Orthopedic therapy of the sagittal dimension can be performed as first-line treatment before transverse correction, when the diagnosis is mandibular retrognathia associated with Brodie syndrome (Fig. 12). The use of an activator with elevation planes or a propeller on splints allows vertical unlocking, which contributes to mandibular sagittal growth. This restoration of occlusal function favors mandibular anterior rotation and allows transversal improvement linked to sagittal growth. Yogosawa 

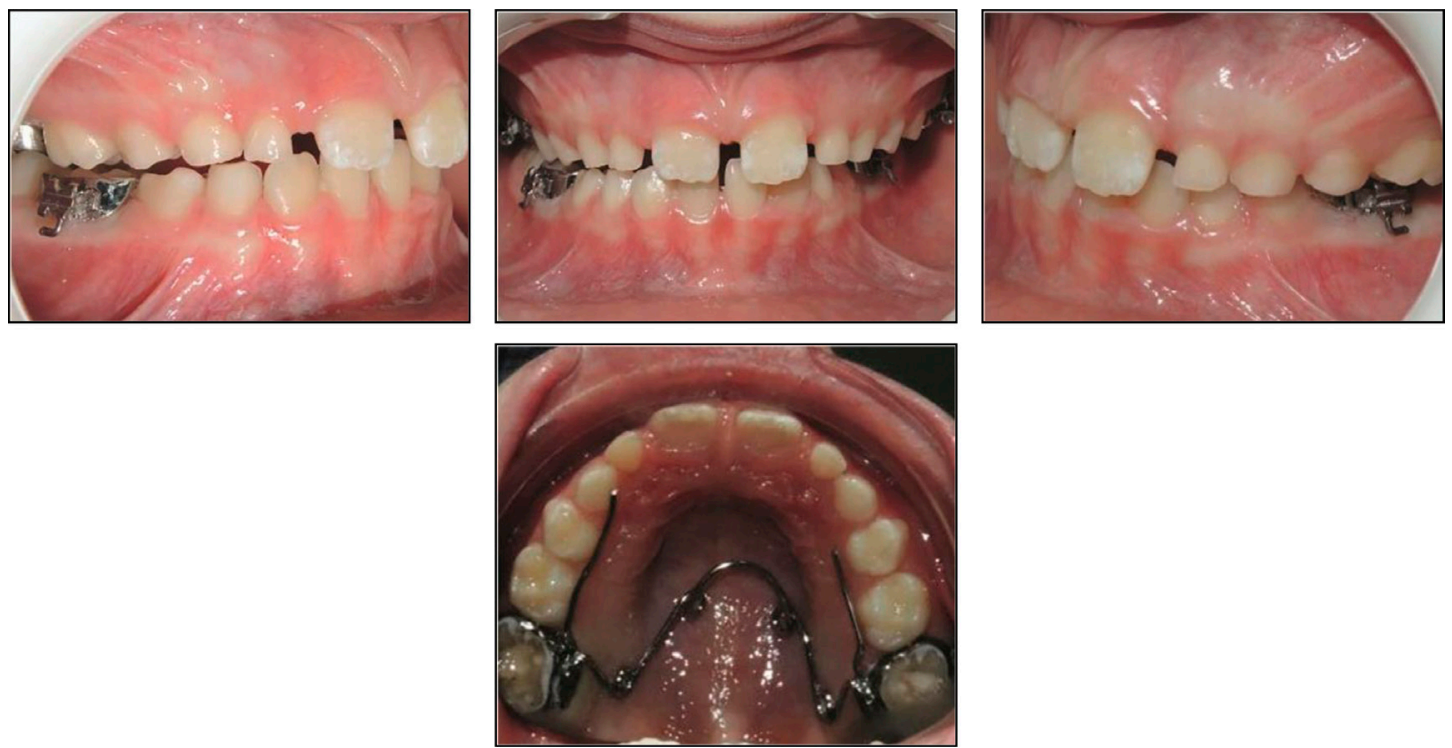

Figure 11

Dr. Cavaré's case: treatment of unilateral Brodie syndrome with contracting Quad Hélix on the maxilla and an expanding Crozat device on the mandible.
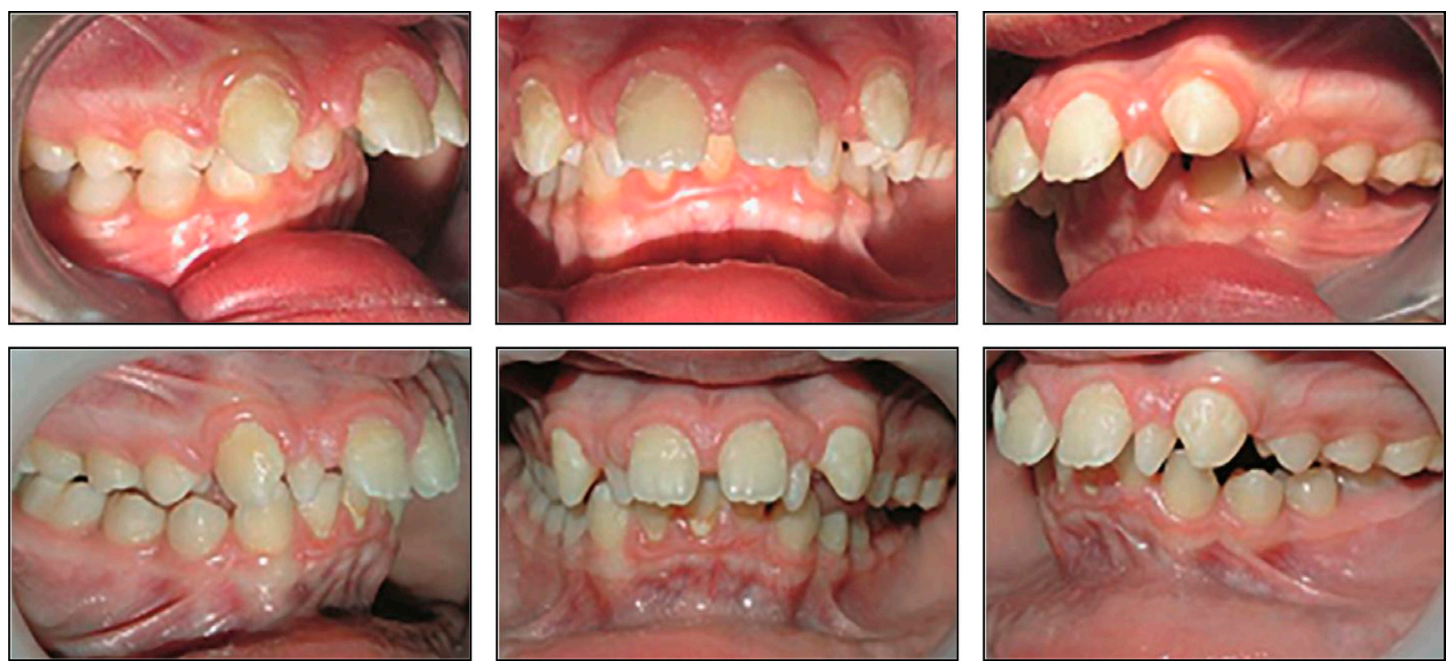

Figure 12

Improvement in transverse relationships after the first phase of sagittal orthopedics in a patient who has William-Buren syndrome (Dr Cavaré).

advocated the use of a maxillary elevation plate shaped at the anterior level to guide the mandible in propulsion (inclination in front and above). This plate caused an hourly rotation of the mandibular plane (approximately $10^{\circ}$ ), which was theoretically unfavorable to skeletal class II correction, which appears to be attenuated once the device is no longer worn ${ }^{21}$. 


\section{Orthodontics}

When the seat of the anomaly is basal (maxillary exognathia and/or mandibular endognathia), orthodontic treatment seeks to compensate occlusally for the transverse shift that exists at the skeletal bases. However, as these alveolar compensations are not accompanied by basal changes, several complications may appear in the long term: periodontal lesions (gingival recessions, bony fenestrations), particularly during vestibuloversion of the lower posterior areas; occlusal instability due to nonphysiological interdental angulations; increased risk of relapse; and lastly, deterioration of smile esthetics. For these reasons, orthodontic compensation treatment should be performed only for patients who have a limited transverse discrepancy of the skeletal bases and/or who have refused to undergo surgery. Apart from these two indications, practitioners have to move toward an orthodontic surgical approach.

In case of Brodie syndrome of alveolar origin (transverse maxillary and/ or mandibular deficiency), orthodontic treatment straightens the pathological alveolar axes and manages the frequent presence of lateral supraocclusion.

\section{Managing lateral supraocclusion}

In bilateral Brodie syndrome, the absence of antagonistic occlusal contacts allows an extrusion of the posterior areas, particularly maxillary, which increases with time. This lateral supraocclusion complicates orthodontic treatment and hinders the movements of the posterior maxillary (palatoversion) and mandibular (vestibuloversion) areas. The management of the supraocclusion requires the use of a removable maxillary elevation plate, which permits an instantaneous and temporary elevation of the occlusion",18. Cooperation of patients is required to ensure that the plate is worn as frequently as possible. This plate is retained until the first occlusal contacts are recovered.

Unilateral Brodie syndrome may also be associated with lateral occlusion on the side of the malocclusion. The occlusal plane then displays a tilt in the frontal plane (lateral tilt) and anteroposterior plane (posterior tilt). To increase the posterior interarch height and treat the affected mandibular area, molar wedges made of resin or cement are placed on the contralateral side at the beginning of treatment (Fig. 13). The discomfort remains significant, and the height of the wedges is gradually reduced. Garcia et al. ${ }^{14}$ proposed another solution that consists of using an elevation plate at the maxillary arch; using a thicker plate on the normal occlusion side conserves sufficient free space $(2 \mathrm{~mm})$ on the opposite side.

\section{Recovering posterior occlusal contact}

Once the lateral supraocclusion is "instantly lifted," multiattachment treatment can be implemented. It is difficult to sustainably equip the mandibular arch (frequent detachment of fasteners or tubes) if the elevation plate is not continuously worn. To avoid this, it may be necessary to combine maxillary vestibular and mandibular lingual multiband treatment ${ }^{21}$. The leveling/ alignment phase was conventionally performed. The mandibular arches can be expanded from the start to initiate recovery of the posterior linguoversed 

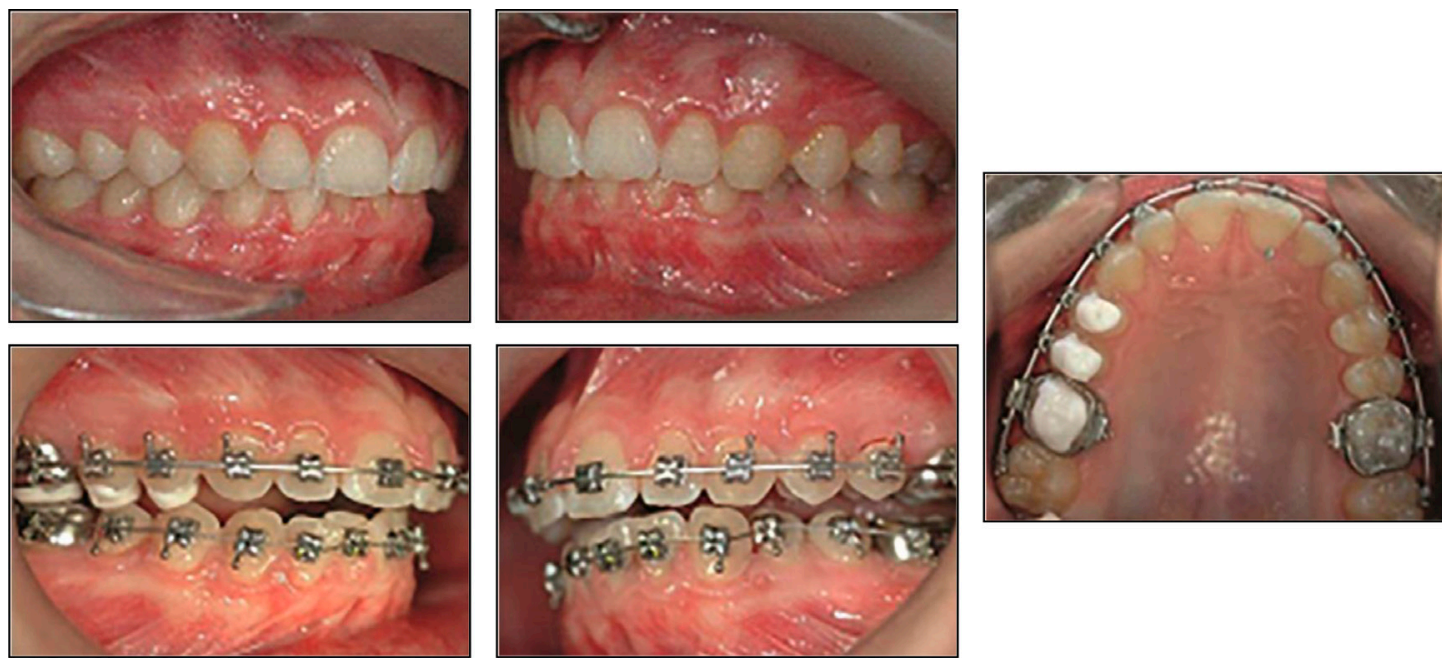

Figure 13

Instantaneous elevation of unilateral supraocclusion by inserting cement wedges on the healthy side (Dr Favali).

areas. Chugh et al. ${ }^{9}$ proposed that at the end of leveling, a steel bow that is large in diameter (.040) should be inserted during expansion and be banded to the final mandibular molars and ligated onto a sufficiently rigid arch.

The addition of coronopalatal lateral torque to the maxilla and coronovestibular torque to the mandible on steel arches with a sufficiently large cross-section initiated the recovery of posterior occlusal contact. In Brodie syndrome, maxillary palatal cusps were often more "extruded"; in fact, the coronopalatal torque effect promoted the simultaneous correction of the transverse direction (contraction) and vertical direction (intrusion).

Some authors have recommended performing treatment combining monomaxillary extractions. The extraction of the first maxillary premolars contributes to the contraction of the arch and the reduction in the overhang. Mandibular extractions are avoided to promote arch expansion, which most often necessitates class II treatment ${ }^{4,18}$.

\section{Intermaxillary traction accessories}

It is possible to use accessories such as intermaxillary tractions "crisscrossed," which are elastic bands stretched between hook clips in the interbracket areas of the maxilla and fasteners glued to the mandibular lingual surfaces (Fig. 14). These elastics allow maxillary palatoversion and mandibular vestibuloversion as well as a decrease in the maxillary intermolar distance and an increase in the mandibular distance. Wearing these tractions requires

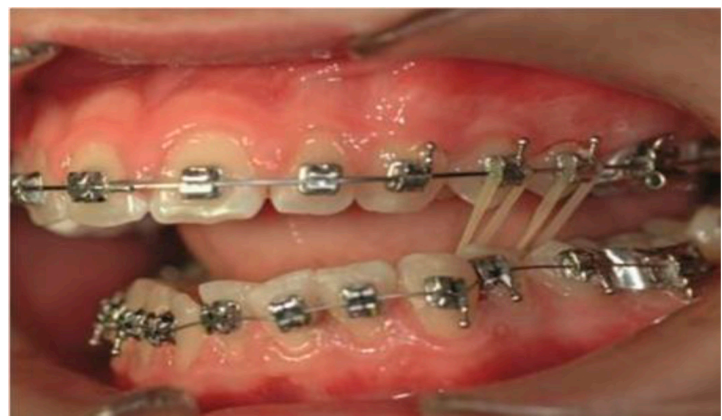

Figure 14

Intermaxillary traction "criss-cross"

(Dr Favali). 
significant cooperation of patients, and the elastics can break if the occlusion is very tight.

Moreover, the action of the elastics was exerted on the two arches, whereas the seat of the malocclusion may concern only one of them.

On the biomechanical plane, an extruded element was exerted on the teeth concerned by wearing the elastic bands. This force, which does not go in the direction of the lateral supraocclusion under correction, can be the cause of several confounding effects: posterior rotation of the mandible (opening of the facial compass) and reduction in the anterior covering can go as far as opening up an anterior gap and creating premature contacts $^{13,20,30}$.

According to Proffit ${ }^{37}$, this extrusion of the molars was compensated for in adolescents by vertical growth of the ramus, which is not the case in adults for whom the elastics must be used with caution. To limit the occurrence of these confounding effects, Chugh et al. ${ }^{9}$ used a combination of high-traction miniscrews (regulated by minor contractions) and muscle chewing exercises. The EOF allowed contraction of the arch (facial arch in contraction) and vertical control of the first molars, which facilitated the crossover of the joint. Chugh et al. obtained closure of an anterior open bite of more than $1 \mathrm{~cm}$; this device required excellent cooperation from patients (frequent use of the helmet and performance of muscular exercises), which resulted in the elastics remaining fixed onto the mandibular arch.

\section{Interest in bone anchorages}

If one wishes to re-establish a posterior occlusal contact without developing extruded forces on the affected teeth, it is advisable to consider switching to bone anchorages together with elastomeric modules or springs set up on each hemiarch. When dealing with patients with Brodie syndrome, miniscrew bone anchorages are preferred because they cost less and are easier to install and use.

In the maxilla, one or several miniscrews were positioned at the medial or paramedial palatal site (the area of the median suture is systematically avoided in growing children), which possesses anatomical conditions favorable to implantation (significant bone volume and thickness of the attached gingiva, absence of anatomical obstacles) ${ }^{35}$. An elastomeric module was stretched between the miniscrew and the button placed on the palatal surface of the affected maxillary teeth. On the vestibular side, a screw was placed between the second premolar and the first molar.

The screw was connected to the brackets/tubes of the vestibular surfaces by an elastomeric chain to support movement. In the mandible, a single miniscrew was placed on the vestibular side between the second premolar and the first molar. An elastomeric module was stretched between the miniscews, and a button was attached to the lingual surface of the concerned mandibular teeth. It was preferable to progressively load the miniscrews, with a force of 30 to $50 \mathrm{~g}$ for the first few activations; 
then, the force was gradually increased to 150-200 $\mathrm{g}$. These devices are limited by the presence of springs or chains at occlusal contact areas, which can rupture in the event of tight occlusion (Fig. 15). At the biomechanical level, by the positioning of the point of application of the forces, these elements combine intrusion movements with maxillary palatoversion and/or mandibular vestibuloversion movements, thus simultaneously correcting the transverse and vertical components of the anomaly.

Finally, corticotomies can be performed to accelerate and facilitate movement. However, the proximity between the miniscrews and the corticotomies may be a source of instability, which does not concern the medial palatal miniscrews. The installation of a miniplate as an alternative is possible,
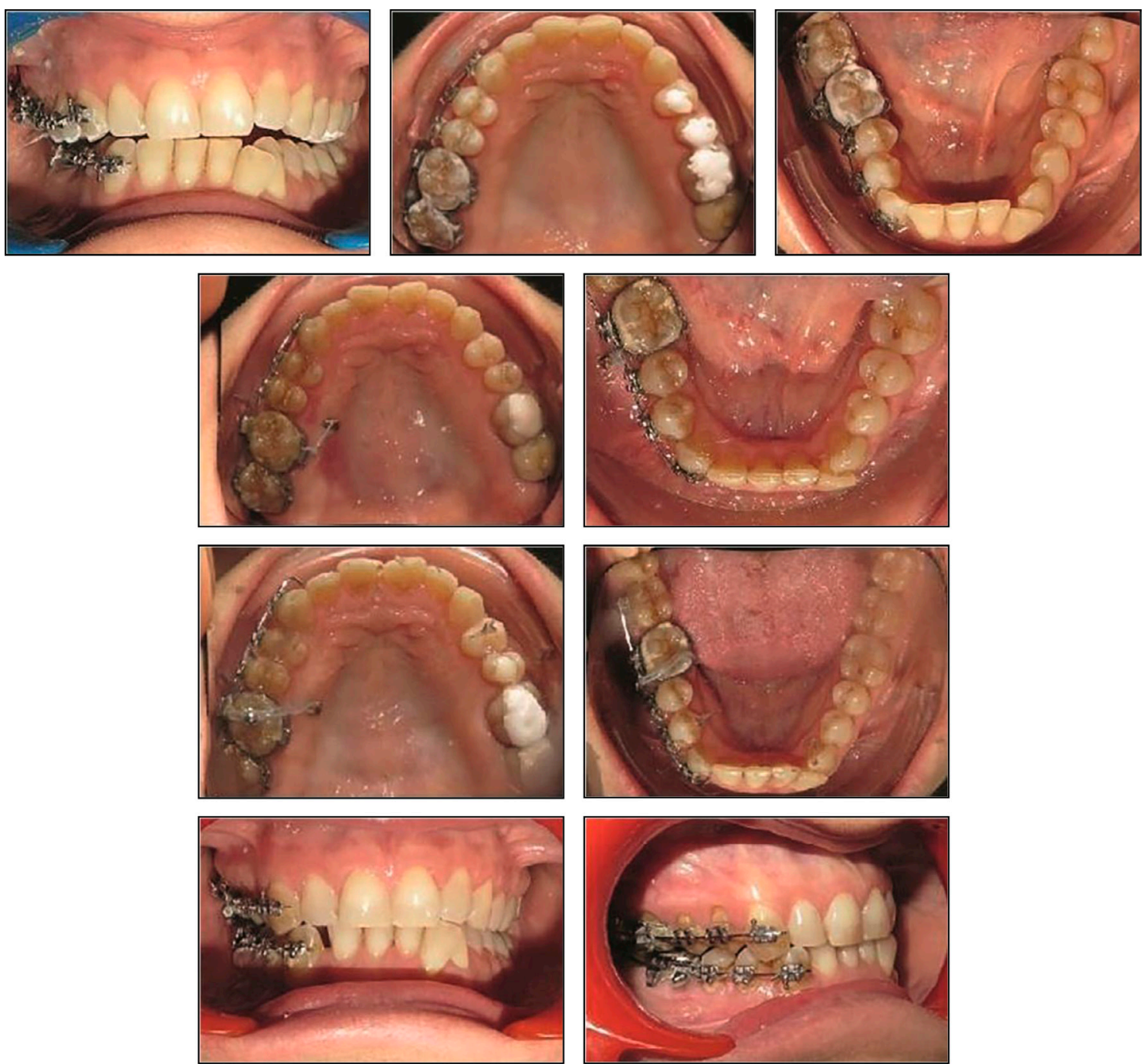

Figure 15

Dr Sebbag's case: unilateral Brodie syndrome treated using two miniscrews and elastic chains. 
but it increases the invasiveness and the cost of treatment.

The use of criss-cross elastics is not indicated in patients with Brodie syndrome as confounding effects linked to the forces of extrusion may accentuate the frontal tilt of the occlusal plane, particularly as lifting wedges are present on the unaffected side. Thus, it is preferable to re-establish an occlusal contact on the affected side by directly attaching the device to the teeth concerned $^{49}$. This one-sided correction is particularly favorable for the use of bone anchorages in combination with elastomeric modules. Jung reported the use of this technique in the treatment of unilateral Brodie syndrome in an adult patient. This resulted in a decrease in the maxillary intermolar width by $2.2 \mathrm{~mm}$ and an increase in the mandibular intermolar width by $5.1 \mathrm{~mm}$ during treatment. The superposition of cephalometric drawings showed intrusions of $4.8 \mathrm{~mm}$ of the first maxillary molar and of $1.4 \mathrm{~mm}$ of the first mandibular molar.

When confronted with a scissor occlusion localized to a pair of antagonistic teeth, it is necessary to determine the seat of the abnormality (maxillary and/or mandibular) to adapt the therapeutic to be put in place. Therapeutic possibilities have been further developed for second molars because they are "terminal" teeth and are most frequently affected by this abnormality, but they may be suitable for other teeth by modifying the design of the devices used and their mechanics.

\section{Removable Technique}

In the literature, only one removable maxillary resin device has been de- scribed, and it was held in place by a vestibular band and Adams hooks located on the first molars. On the side of the scissor joint, a helix extended by a very wide buccal arm (.040) was welded to the Adams hook to face the second molar. Activation at the vestibular arm facilitated the palatoversion of this tooth. Moreover, the maxillary plate may include the occlusal surface of the first molars and premolars to facilitate the passage of the joint. The effectiveness of treatment depends on the cooperation of patients.

\section{Fixed Techniques}

Kucher and Weiland ${ }^{27}$ proposed the use of a transpalatal arch connected to the first maxillary molars, equipped with hooks welded to the transpalatal area in the posterior direction so that the end of the hook was slightly more posterior and apical than the second molars. A button was bonded to the palatal surfaces of these teeth and tensioned in the elastomeric chain between the transpalatal hook and the bonded button (Fig. 16). A vestibular sectional arch can be added. This "palatal technical intrusion" allows the application of a combination of forces on the tooth, incorporating intrusion, palatal coronoversion, and vestibular radial torque control.

Nakamura ${ }^{29}$ and Reddy ${ }^{41}$ placed the chain between the transpalatal welded hook and the vestibular tube of the second molar band; the chain then passed over the occlusal surface of the tooth. This technique made it possible to increase the intrusion component as well as the cornopalatal version applied to the second molar, but the chain can break during the passage of the joint. 

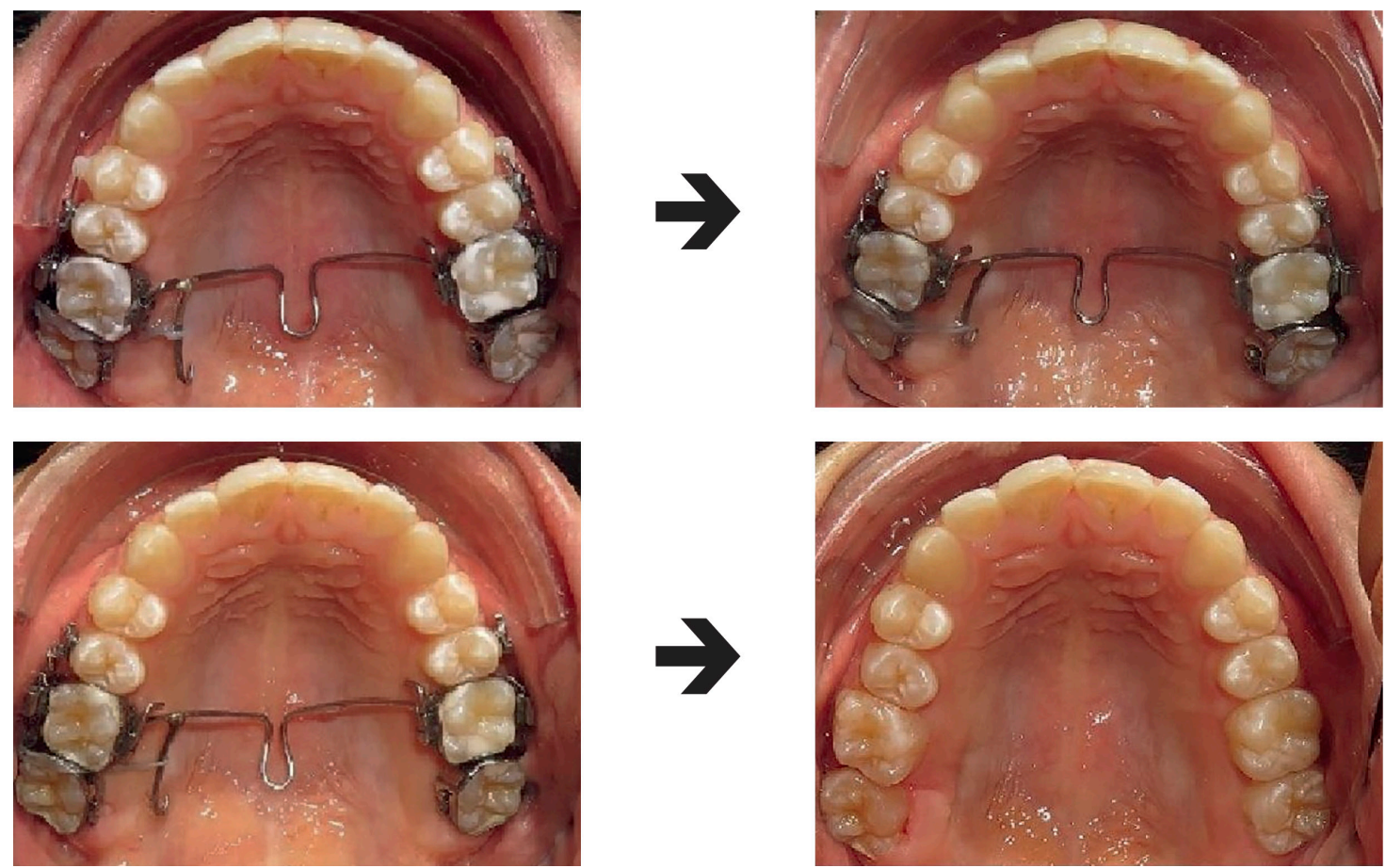

Figure 16

Dr. Sebbag's case: correction of Brodie occlusion on 16 confined by the use of a welded hook on a goshgarian and sectorial vestibular treatment.

This device, which is simple to use, facilitates rapid correction (2-3 months) of the unilateral or bilateral scissors occlusion ${ }^{28}$. It requires perfect intraoral adaptation to avoid patient discomfort, and gingival irritation may occur if hygiene is poor.

Nakamura $^{29}$ used the same system by adapting it to the mandibular arch. The device consisted of a lingual arch connected to the first mandibular molars and a portion of this arch was welded to the vestibular surface of the bands to be posteriorly positioned in relation to the affected teeth. A button was bonded to the lingual surfaces of these teeth, and an elastomeric chain was tensioned between the arch and the bonded button. As soon as the molars were adjusted, a sectional arch from the second premolar to the second molar could be added to improve torque control and strengthen the anchorage.

A Quad Helix, which is activated in the contraction mode, can be used in the maxilla, as seen previously. The correction of the exaggerated articulation is only made on the two banded teeth. It is possible in more extensive cases to add vestibular lateral arms. In unilateral cases, correction of the scissor occlusion is achieved by adding vestibular radial torque at the molar level reached, which is then accompanied by intrusion of this tooth and confounding extrusion of the contralateral molar anchorage. This confounding effect is largely counterbalanced by occlusal forces. 


\section{Techniques using bone anchorages}

The use of a bone anchorage device in a direct technique makes it possible to eliminate confounding effects associated with the use of conventional techniques. In the maxilla, a miniscrew is positioned at the level of the palatal alveolar rampart, preferably between the second premolar and the first molar, to avoid damaging the vasculonervous bundle present near the second mo$\operatorname{lar}^{24}$. An elastomeric chain is stretched between the miniscrew and the vestibular tube of the second molar. At the mandible, the miniscrew is vestibular, between the second premolar and the first molar. Likewise, an elastomeric module is stretched between the miniscrew and a button bonded on the lingual surface of the second molar to straighten and intrude this tooth. The scissor joint correction is done in 3-4 months.

Bone anchorages can also be indirectly used, such as in the "Dragon $\mathrm{He}$ lix Appliance" 49 . The miniscrew located between the first and second premolars is connected to the first molar by a $.019 \times .025$ steel arch bonded to its vestibular surface. The motive force is delivered to the second molar by way of the "dragon helix" spring and is bonded in compression by its extremities on the vestibular surface and on the occlusal surface of the second molar.

\section{Causal teeth extractions}

According to Quinn ${ }^{38}$, the presence of a scissor joint located in the second molars may justify their extraction and replacement by wisdom teeth. In adults, when wisdom teeth are present on the arch, it is necessary to control their morphology, size, and periodontal environment before extracting the second molars. Mesialization is then performed to put the wisdom teeth in contact with the first molars. During adolescence, although the eruption of wisdom teeth cannot be predicted with certainty, these teeth can be placed mesially near the first molar. This therapeutic choice seems more complex to implement if the causal tooth is the first molar, but in scissor occlusions affecting the premolars and if extractions are necessary for other reasons, it may be preferable to choose to extract the affected premolars.

\section{Surgery}

While many orthodontic treatments can be used, the complexity of the treatment of lateral supraocclusion and the significant deformations of the arches that worsen over time often suggest the need for orthodontic surgical treatment. Surgery also seeks to obtain maxillary contraction and/or mandibular expansion. Lateral supraocclusion and any sagittal and vertical skeletal abnormalities are corrected in the same surgical procedure.

Two types of surgery have been reported in the literature to obtain maxillary basal contraction.

Schuchardt segmental osteotomy

Surgeons can perform sectoral contraction using Schuchardt segmental osteotomy ${ }^{8}$. This posterior subapical osteotomy facilitates the unilateral or bilateral mobilization of the premolarmolar areas essentially for the purpose of intrusion; however, movements of the coronolingual version can be associated. Orthodontic preparation is often necessary and aims to conserve 
or aggravate the supraocclusion of the affected lateral areas ("staircase step" arch). Of particular interest in the case of unilateral Brodie syndrome with lateral supraocclusion, this intervention is practiced less because of the risks of devascularization and pseudarthrosis in the mobilized sector.

\section{Lefort I osteotomy with maxillary contraction}

To the standard characteristics of "classical" Lefort I osteotomies, a second-stage intermaxillary disjunctor is added to the maxilla. Median anterior triangular bone resection is performed with a wide ball nose cutter to resect a reasonable bone volume. Posterior contraction of the arch is thus obtained after approximation of the right and left hemimaxillaries. A maxillary splint made from presurgical study models ensures the correct positioning of the right and left sectors before fixing them with titanium plates. Given the thickness of the palatal mucosa, this technique allows a maximum contraction of approximately $5-6 \mathrm{~mm}$. The palatal mucosa must not be affected to not risk oral communication ${ }^{5,14}$. According to Beziat ${ }^{3}$, the stability of this intervention does not pose a problem.

Ramsay et al. ${ }^{40}$ performed Lefort I osteotomy (three dental segments) on a patient with Brodie syndrome with posterior impaction to correct the associated lateral supraocclusion. This cutting pattern is used in the presence of palatal torus but requires the extraction

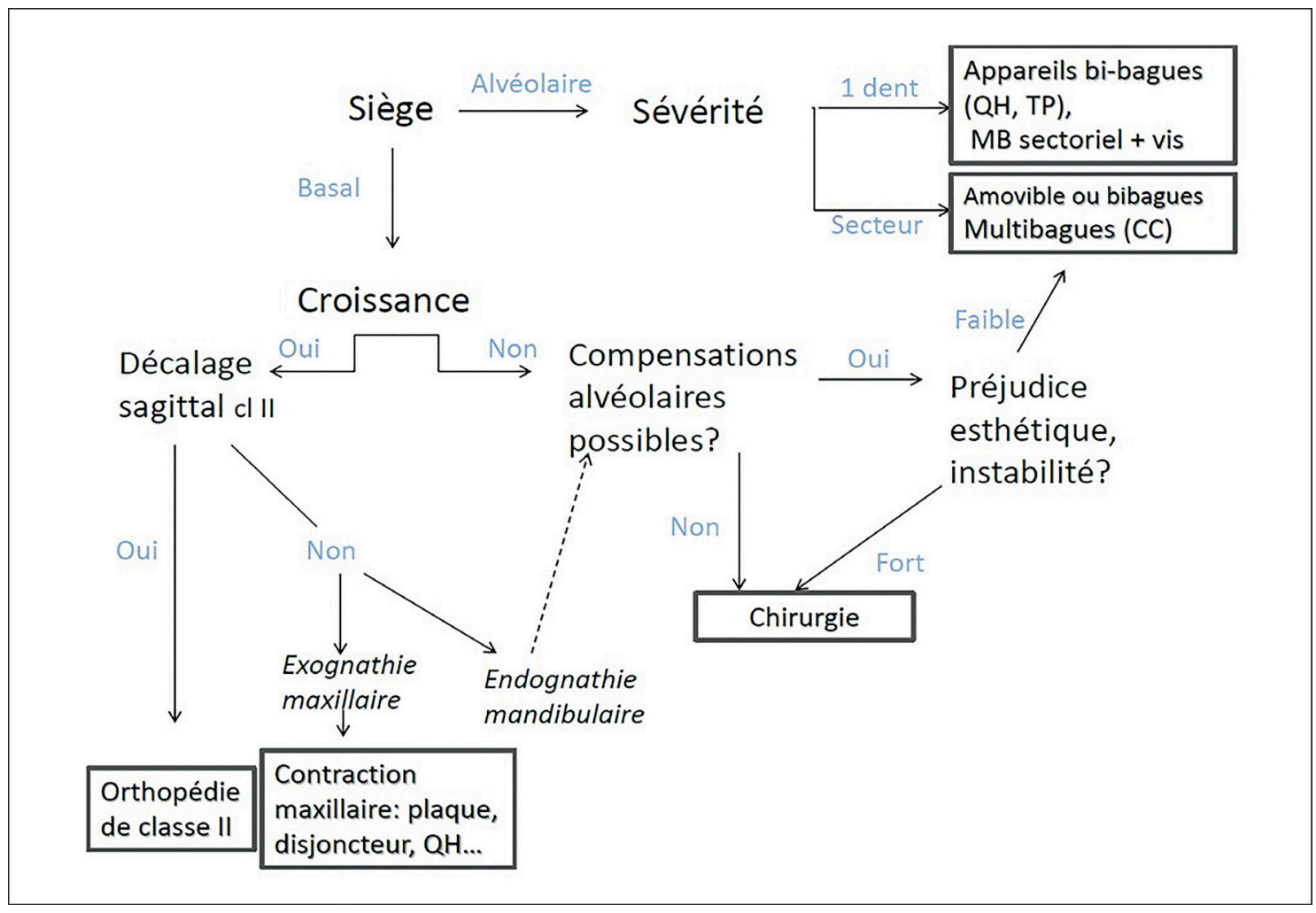

Figure 17 
of the first maxillary premolars to create the osteotomy line. Krekmanov et al. ${ }^{26}$ created several osteotomy lines parallel to each other in the maxilla. Each bone segment should be kept fixed at the periosteum to promote healing. This type of osteotomy makes it possible to better distribute tensions at the basal level and to limit the amount of shaping required on the palatal arc. However, care should be taken to avoid contact with the greater palatine artery when performing lateral osteotomies. Garcia et al. ${ }^{14}$, in the treatment of unilateral Brodie syndrome, proposed Lefort I osteotomy in conjunction with median contraction and superior osteotomy on the affected side to simultaneously correct lateral supraocclusion.

Surgical mandibular expansion has been described in three ways: segmental surgery (posterior subapical osteotomy), mandibular expansion osteotomy, and symphyseal distraction.

\section{Posterior subapical segmental osteotomy}

Posterior subapical osteotomy is indicated in unilateral Brodie occlusions with strong deformations of the mandibular arch. A premolar-molar segment is isolated and can be repositioned in different directions. Initially described by Macintosch, this surgery has rarely been used because it carries risks of injury to the lower alveolar nerve and as the vascularization of the dissected segment is a critical issue. However, this surgery has not been abandoned and was recently used by Suda et al. ${ }^{44}$ for the treatment of a 21-year-old woman with unilateral Brodie syndrome and a very deformed mandible. At the end of treatment, the authors noted that the mandibular bone was intact and that there was no damage to the alveolar dental nerve. Cureton et al. ${ }^{11}$ also used this technique in conjunction with bilateral sagittal osteotomy of mandibular advancement in the treatment of a patient with a class II division 1 type with unilateral Brodie syndrome.

Orthodontic preparation with the "staircase step" arches promotes the surgical action of impaction. Once the osteotomy has been made, the premolar-molar segment can be moved to its new position using an intermediate repositioning plate preoperatively made using study models. It can also be postoperatively moved with the placement of a gradually activated modified lingual arch until functional occlusion is restored.

\section{Mandibular expansion osteotomy}

Mandibular expansion osteotomy consists of median or paramedial surgical separation of the mandible. The fragments are repositioned by rotating and translating movements at the bottom and at the desired locations and are stabilized by means of plates and screws. A bone graft is necessary to fill the lack of continuity created. Garcia ${ }^{14}$ described the association of symphyseal osteotomy with a classical sagittal rift to correct transverse dysmorphosis. The posterior rift and anterior dissociation cause a movement below and outside the two hemiarches (if the syndrome is unilateral, this movement is only visible on the affected side).

This technique only allows a limited amount of expansion with a high risk of relapse and leads to gingival tears and periodontal problems. It is currently avoided in favor of symphyseal distraction ${ }^{12}$. 


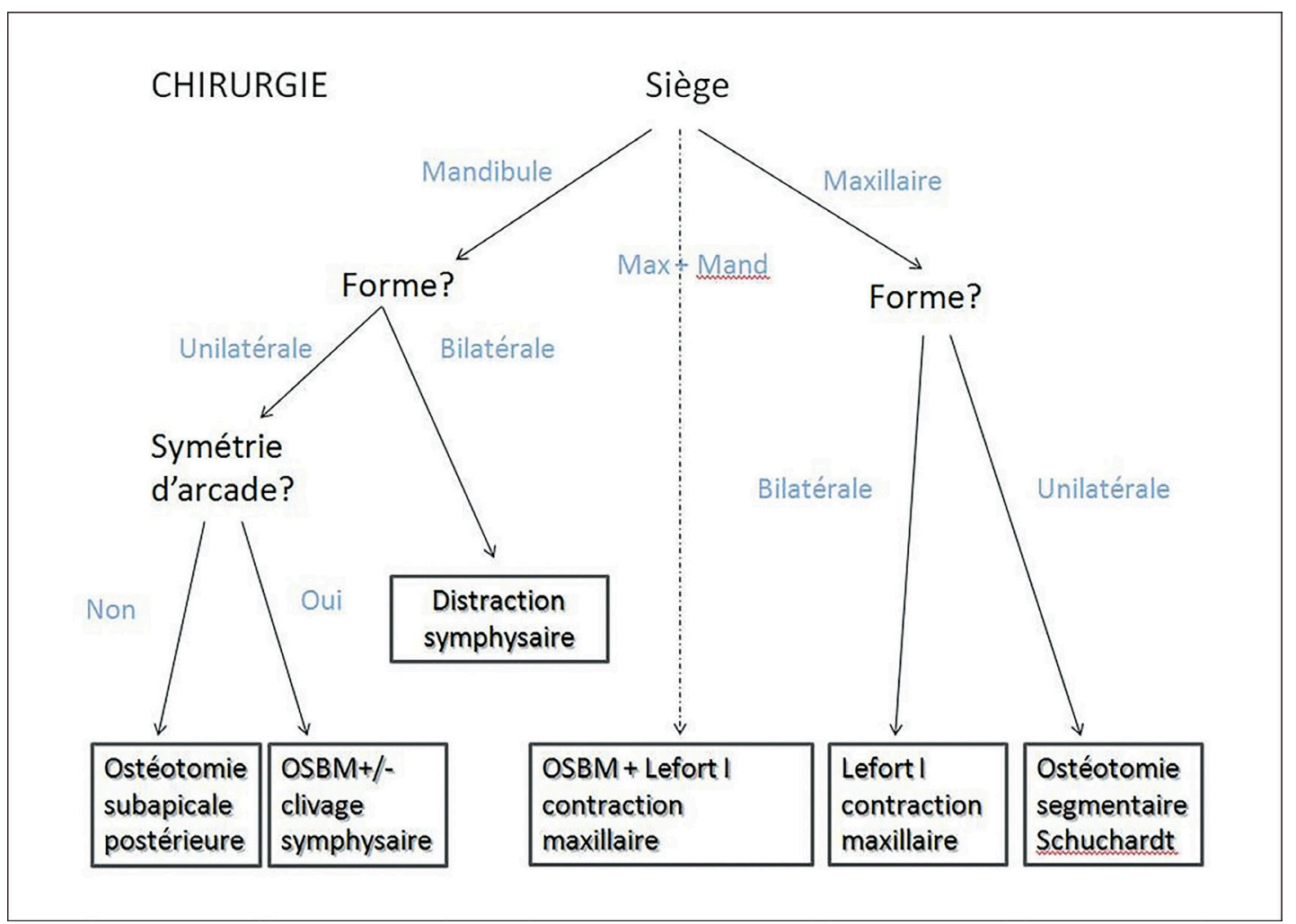

Figure 18

\section{Symphyseal bone distraction}

After vertical interdental symphyseal osteotomy, symphyseal bone distraction consists of the creation of an osteogenic site in the osseous interval generated. The two surgically separated hemimandibles are progressively separated from each other by activating the distractor, thus causing bone regeneration. By exploiting natural bone repair, it is now possible to stably increase the mandibular transverse dimension ${ }^{36}$.

A presurgical orthodontic preparation is necessary in case of Brodie syndrome. The leveling of the maxillary arch and the emergence of a lateral supraocclusion allows mandibular expansion without occlusal interference.
To avoid dental complications (fracture, root exposure) during osteotomy, some authors recommend that orthodontic root axes should be diverted to eliminate root proximities and thus increase the amount of alveolar bone available between the incisors. After the elevation of a fully thick flap, the procedure consists of interdental vertical osteotomy beginning at the basilar edge and stopping at the interdental septum. Osteotomy is currently performed using Piezotome, which has a very fine and precise section, and is conducted with a spatula in the interdental area. To limit the risk of root fractures, a cut is vertically made between the two mandibular central incisors in an area where the alveolar bone thickness is 
sufficient. This type of osteotomy is indicated for bilateral Brodie syndrome in which symmetrical expansion of the skeletal base is sought.

In case of unilateral Brodie syndrome, asymmetrical expansion is sought to unilaterally widen the mandibular base. Guerrero et al. recommended performing vertical parasymphyseal osteotomy on the affected side (ipsilateral) between the lateral canine and the incisor16. Legan suggested classic symphyseal distraction combined with the use of criss-cross intermaxillary traction to increase or inhibit expansion along the sides ${ }^{12}$. King proposed conducting medial symphyseal distraction associated with the use of a maxillary resin splint that has deep indentations on the side in normal occlusion and a sliding plane on the affected side ${ }^{23}$. Finally, Tae et al. advocated making a "staircase step" osteotomy line combined with an obliquely oriented hybrid distractor ${ }^{45}$.
A latency period of approximately 7 days must be observed before initiating the removal of the bone banks. This rest period corresponds to the time required for the initiation of bone healing. The distraction phase consists of the slow and progressive spreading of the two bone segments, allowing the bone to regenerate and extend. After reaching the desired amount of expansion (corrected posterior joint), the distractor is held in place for 2-3 months (bone consolidation phase). At the end of this period, the distractor is removed and then replaced by a passive lingual arch to ensure that the expansion is restrained. The mean expansion found in studies was $7 \mathrm{~mm}$. Independent of the type of distractor used (with dental or bone anchorages), the point chosen to apply force must be in an anterior area of the mandible: the effects of distraction are therefore maximum in the incisivo-canine area and they then gradually decrease toward the second molars ${ }^{36}$.

Symphyseal bone distraction is currently the most appropriate solution to correct transverse skeletal mandibular defects.

Conflict of interest: The authors have no conflict of interest.

\section{BIBLIOGRAPHY}

1. Bassigny F. L'examen de la cavité buccale. EMC 1988;23:460-10. Biourge MA. Macroglossie et microglossie. Orthod Fr 37. 1966;345-351. 
2. Bassigny F. Signes majeurs et signes associés des anomalies orthodotiques. Sémiologie orthodontique. EMC - Odontol Dentofaciale Artic 23-460-C-10.

3. Béziat J-L. Chirurgie de la dimension transversale. Orthod Fr 2011;82(2):159-169.

4. Boileau M-J. Orthodontie de l'enfant et du jeune adulte - Traitement des dysmorphies et malocclusions - Tome 2. Elsevier Masson, 2011.

5. Bouletreau P, Paulus C. Correction chirurgicale des anomalies squelettiques transversales maxillo-mandibulaires. Int Orthod 2012;10(3):261-273.

6. Bouvet J-M. Diagnostic des anomalies transversales en orthopédie dento-faciale. Rev Orthopédie DentoFaciale 1974;8(4):505-509.

7. Brodie AG. Consideration of musculature in diagnosis, treatment, and retention. Am J Orthod 1952;38(11):823835.

8. Charrier J-B. Chirurgie orthognathique de l'adulte et esthétique faciale. Rev Orthopédie Dento-Faciale 2012;46(2):141-163.

9. Chugh VK, Sharma VP, Tandon P, Singh GP. Brodie bite with an extracted mandibular first molar in a young adult: a case report. Am J Orthod Dentofacial Orthop 2010;137(5): 694-700.

10. Conley R, Legan H. Mandibular Symphyseal Distraction Osteogenesis: Diagnosis and Treatment Planning Considerations. Angle Orthod 2003;73(1):3-11.

11. Cureton SL, Bice R, Strider J. Treatment of a Class II Division 1 malocclusion with a severe unilateral lingual crossbite with combined orthodontic/orthognathic surgery. Am J Orthod Dentofacial Orthop 2000;117(6):728-734.

12. Dahan J. Les perturbations linguales dans les déformations maxillaires. Aspect nosologique et concepts thérapeutiques. Rev Orthopédie Dento-Faciale 1989;23(1):53-67.

13. Deniaud J. Quad Helix : approche fondamentale et orthopédique. Rev Orthopédie Dento-Faciale 1995;29(2):241-249.

14. Garcia R, Simon A, Vergnes-Bacqué N. Traitement chirurgico orthodontique du syndrome de Brodie asymétrique. J Edge 1994;31:41-54.

15. Gelin ME. Treatment and retention of a mandibular arch telescoped within the maxillary arch: case report. Pediatr Dent 1991;13(3):167-169.

16. Guerrero CA, Bell WH, Contasti GI, Rodriguez AM. Mandibular widening by intraoral distraction osteogenesis. Br J Oral Maxillofac Surg 1997;35(6):383-392.

17. Guezenec P. Cas particulier. Cas complexes. L'orthodontie Bioprogressive 2010.

18. Harper DL. A case report of a Brodie bite. Am J Orthod Dentofacial Orthop 1995;108(2):201206.

19. Hua X, Xiong H, Han G, Cheng X. Correction of a dental arch-width asymmetric discrepancy with a slow maxillary contraction appliance. Am J Orthod Dentofacial Orthop 2012;142(6):842-853.

20. Ishihara Y, Kuroda S, Sugawara Y, Kurosaka H, TakanoYamamoto T, Yamashiro T. Longterm stability of implant-anchored orthodontics in an adult patient with a Class II Division 2 malocclusion and a unilateral molar scissors-bite. Am J Orthod Dentofacial Orthop 2014;145(4):100-113.

21. Jung M-H. Traitement d'un syndrome de Brodie unilatéral sévère, avec des mini-vis orthodontiques chez un adulte d'âge moyen. Orthod Fr 2012;83(4):275-288.

22. Kholoki S. Quad Helix : approche orthodontique et clinique. Rev Orthopédie Dento-Faciale 1995;29(2):251258. 
23. King JW, Wallace JC. Unilateral Brodie bite treated with distraction osteogenesis. Am J Orthod Dentofacial Orthop 2004;125(4):500-509.

24. Kravitz ND, Kusnoto B. Risks and complications of orthodontic miniscrews. Am J Orthod Dentofacial Orthop 2007;131(4):43-51.

25. Kravitz ND. Treatment with the mandibular Arnold expander. J Clin Orthod 2014;48(11): 689-696.

26. Krekmanov L, Kahnberg K-E. Transverse surgical correction of the maxilla: A modified procedure. J Cranio-Maxillofac Surg 1990;18(8):332-334.

27. Kucher G, Weiland FJ. Goal-oriented positioning of upper second molars using the palatal intrusion technique. Am J Orthod Dentofacial Orthop 1996;110(5):466-468.

28. Lim K. Correction of posterior single-tooth crossbite. J Clin Orthod 1996;30(5):276.

29. Nakamura S, Miyajima M, Nagahara K, Yokoi Y. Correction of single-tooth crossbite. J Clin Orthod 1995;29:257-262.

30. Nocini PF, Salgarelli A, Consolo U, Bertossi D, Faccioni F. Brodie's syndrome. A report of 2 atypical cases. Minerva Stomatol 1995;44(7-8):361-368.

31. Nojima K, Takaku S, Murase C. A case report of bilateral Brodie bite in early mixed dentition using bonded constriction quad-helix appliance. Bull Tokyo Dent Coll 2011;52(1):39-46.

32. O'Grady PW, McNamara Jr JA, BaccettiT. A longterm evaluation of the mandibular Schwarz appliance and the acrylic splint expander in early mixed dentition patients. Am J Orthod Dentofacial Orthop 2006;130(2):202-213.

33. Ogihara K, Nakahara R, Koyanagi S. Treatment of a Brodie bite by lower lateral expansion: a case report and fourth year follow-up. J Clin Pediatr Dent 1998;23(1):17-21.

34. Pajoni D. Vingt questions d'internat en ODF. Éditions SID, 1997.

35. Park H-S, Jeong S-H, Kwon O-W. Factors affecting the clinical success of screw implants used as orthodontic anchorage. Am J Orthod Dentofacial Orthop 2006;130(1):18-25.

36. Pascon L, Bazert C, Bardinet E. Apport de la distraction osseuse symphysaire dans nos stratégies thérapeutiques. Rev Orthop Dento Faciale 2016;50:123-139.

37. Profitt W. Contemporary Orthodontics. 1st ed. St. Louis : CV Mosby Co., 1986.

38. Quinn GW. Extraction of four second molars. Angle Orthod 1985;55(1):58-69.

39. Raberin M. Pathologies et thérapeutiques de la dimension transversale en denture mixte. Conséquences sur l'équilibre musculaire. Orthod Fr 2001;72(1-2):131-142.

40. Ramsay DS, Wallen TR, Bloomquist DS. Case report MM. Surgical-orthodontic correction of bilateral buccal crossbite (Brodie syndrome). Angle Orthod 1990;60(4):305-311.

41. Reddy V, Reddy R, Parmar R. A modified transpalatal arch for correction of scissor bite. J Clin Orthod 2012;46(5);308-309.

42. Ricketts RM. Cephalometric Analysis And Synthesis. Angle Orthod 1961;31(3):141-156.

43. Sachiko H, Jun-ichi W. Occlusal guidance for unilateral scissors bite in primary dentition: A case report. Pediatr Dent J 2007;160-166.

44. Suda N, Tominaga N, Niinaka Y. Orthognathic treatment for a patient with facial asymmetry associated with unilateral scissors-bite and a collapsed mandibular arch. Am J Orthod Dentofacial Orthop 2012;141(1):94104.

45. Tae KC, Kang KH, Kim SC. Unilateral mandibular widening with distraction osteogenesis. Angle Orthod 2005;75(6):1053-1060.

46. Valencia RM. Treatment of unilateral buccal crossbites in the primary, early mixed, and permanent dentitions: case reports. J Clin Pediatr Dent 2007;31(3):214-218. 
47. Yogosawa F. Case report AE. Non-surgical correction of a severe Class II malocclusion (Brodie syndrome). Angle Orthod 1990;60(4):299-304.

48. Yun SW, Lim WH, Chong DR, Chun YS. Scissors-bite correction on second molar with a dragon helix appliance. Am J Orthod Dentofacial Orthop 2007;132(6):842-847. 